\title{
https://doi.org/10.30681/real.v14.4965
}

\section{PICHAÇÃO: UMA ANÁLISE DA PAISAGEM LINGUÍSTICA NO CENTRO DA CIDADE DE MANAUS}

Laíza Bezerra MACIEL ${ }^{1}$

Resumo: A prática da pichação na cidade de Manaus compreende diferentes modos de interação com a sociedade, utilizando dos muros de casas e prédios como suporte para uma expressão artística ou crítica. O presente estudo dedica-se à análise dos aspectos linguísticos presentes nas pichações do Centro e localidades adjacentes de Manaus e, para isso, a pesquisa baseia-se em uma coleta de material com cerca de cento e vinte imagens realizadas. Dessa forma, destaca-se a importância da pichação como uma prática de uso da linguagem, a partir de perspectivas de autores das áreas da Linguística e das Artes Plásticas, tais como Eni Puccinelli Orlandi e Gustavo Lassala.

Palavras-Chave: pichação; linguagem; discurso; pichadores

\begin{abstract}
The practice of picho in the city of Manaus comprises different modes of interaction with society, using the walls of houses and buildings as a support for artistic or critical expression. The present study is dedicated to the analysis of the linguistic aspects present in the picho of downtown and adjacent locations of Manaus and, for this, the research is based on a collection of material with about one hundred and twenty imagens made. Thus, the importance of picho as a practice of using language is highlighted, from the perspectives of authors in the areas of Linguistics and Plastic Arts, such as Eni Puccinelli Orlandi and Gustavo Lassala.
\end{abstract}

Keywords: picho; language; speech; picho writers

\section{INTRODUÇÃO}

A prática de pichar pode ser compreendida como ato de escrever sobre muros e fachadas de prédios com tinta em spray aerossol, representando necessariamente formas de intervenção do espaço urbano. As pichações são expressas, muitas vezes, por simbologias e pela utilização de vocabulário específico que demonstram a atuação de um grupo e também servem de comunicação entre um grupo e outro. Os bairros e as localidades também possuem importância, pois são vistos como território para estabelecer limites sociológicos à liberdade individual e isso contribui para as produções.

1 Acadêmica do Curso de Letras na Universidade Federal do Amazonas - UFAM. Manaus/AM. laizamaciel@hotmail.com. 


\section{Revista de Estudos Acadêmicos de Letras}

Os grafismos urbanos são manifestações linguístico-culturais utilizadas, em muitos momentos, como expressão de protestos e reivindicações. A prática da pichação e do grafite empregam linguagens diferentes de interação com a sociedade, no entanto aproveitam do mesmo suporte: os muros e os edifícios de cidades. Desse modo, o estudo sobre a linguagem dos pichadores permite compreender as diferenças linguísticas associadas às circunstâncias de comunicação, tais como tipo de texto, assunto da mensagem, modalidade dos discursos, lugar de interação e entre outros fatores.

Para isso, a presente pesquisa atém-se a proposta teórico-metodológica da Análise de discurso, a qual se ocupa com o uso da língua em interação com construções ideológicas, especialmente com o estudo da linguagem inserida em um contexto histórico e social de determinada comunidade de fala. Trata-se de uma investigação qualificativa que visa analisar os aspectos linguísticos presentes na prática da pichação no espaço urbano manauara, sob a ótica das obras da professora Orlandi (2002) e do linguista Maingueneau (2015).

Tem-se, por consequência, uma pesquisa de caráter etnográfico, haja vista a necessidade de coleta de dados principalmente com o uso de câmera fotográfica para realizar uma descrição de recursos da linguagem encontrados na paisagem da cidade. Sob esse cenário, é interessante afirmar que as pichações constituem práticas cotidianas de uso da linguagem e destacam diferentes formas de representações dos espaços.

Evidencia-se, assim, uma discussão imprescindível a todas as esferas da sociedade, pois busca superar questões ligadas a preconceitos e julgamentos em relação à pichação e ao grafite, além de direcionar para desestabilização de discursos consolidados em que arte refere-se apenas àquelas aceitas por uma classe social prestigiada. 


\section{Revista de Estudos Acadêmicos de Letras}

\section{GRAFITE E PICHAÇÃO: CONCEITOS E ESTILOS}

O grafite e a pichação constituem intervenções urbanas contemporâneas que são recursos expressivos distintos na arte de rua. Ambos convidam os transeuntes das grandes cidades a um momento de reflexão e fruição estética, além de causarem um sentimento de estranhamento ao leitor. O uso de cores, linhas e formas chamativas, além dos temas abordados nas inscrições de muros são, muitas vezes, críticas de cunho social, político ou simplesmente assinaturas utilizadas para marcação de atuação territorial de grupos.

Embora sejam duas manifestações distintas, não é possível compreender e analisar apenas a pichação sem mencionar o grafite, visto que possuem, segundo Franco (2009, p. 20), uma comunhão subterrânea tanto na história da prática como nas interdependências processuais para interferirem na cidade. Dessa forma, em um primeiro contato com esse universo, é admissível afirmar que existem pelo menos três aspectos em comum entre as duas ações.

Um aspecto em comum entre as duas práticas está relacionado ao ponto de vista da legalidade. O grafite e a pichação são considerados infrações penais, tipificadas na Lei de Crimes Ambientais, mais especificamente Art. 65 e seus parágrafos da Lei 9.605/98. Ainda que ambos sejam ilícitos, os grafiteiros têm melhor aceitação para sua prática, em razão da estética elaborada de imagens com humor e descontração, o que fez a coibição recair com mais intensidade sobre a pichação e, consequentemente, ser retratada como ato de vandalismo diante da mídia brasileira.

O segundo aspecto de congruência entre a pichação e o grafite deve-se ao fato dos interventores atuarem, de forma transitória, pelas duas expressões, sendo razoável afirmar que são realizadas concomitantemente. O grapixo é um exemplo dessa correlação, pois decorre de uma "fase intermediária entre a pixação e o grafite e é caracterizada por letras desenvolvidas por pichadores em São Paulo com a adição de duas ou mais cores no contorno e miolo das letras [...]" (LASSALA, 2017, p. 52).

O terceiro ponto em comum dá-se na relação interacional entre os grupos de atuação de arte de rua. Os grafismos urbanos são geralmente produzidos em conjunto, em razão de serem consideradas práticas marginalizadas, os interventores atuam em grupos, auxiliando uns aos outros a fim de agilizar a produção. Em relação a isso, a atuação em conjunto na comunidade de pichadores gera um conflito social, de modo que, conforme Azevedo (2014, p. 44), vê-se uma disputa entre grupos de pichadores sobre a utilização dos espaços da cidade. 


\section{Revista de Estudos Acadêmicos de Letras}

Apontadas as perspectivas de aproximação entre o grafite e a pichação, a principal dificuldade do observador é a diferença entre as duas manifestações gráficas. Em relação a isso, o conceito de singularização dessas expressões culturais pode ser simples: "uma das diferenças entre o graffitti e a pichação é que o primeiro advém das artes plásticas e o segundo da escrita, ou seja, o graffiti privilegia a imagem; a pichação, a palavra e/ou a letra" (GITAHY, 1999, p. 12).

A palavra graffiti significa inscrição ou desenhos de épocas antigas realizadas com carvão em rochas e paredes. Para Gitahy (1999), as pinturas rupestres são os primeiros exemplos de graffiti que encontramos na história da arte e, ao longo dos anos, as técnicas e os materiais utilizados para essa prática foram sendo aprimorados com o intuito de expressão comunicativa.

O grafite consagra-se como linguagem artística no Brasil no fim dos anos de 1970 com a influência de artistas Keith Haring e Kenny Scharf, conquistando seu espaço na mídia e por intermédio de manchetes de jornais e Bienais. Ainda segundo o artista Gitahy (1999), o grafite, na sua essência, exige maior complexidade em sua elaboração, pois são utilizadas técnicas de noções de movimento, cor, luz, volume e outros recursos como colagens ou adesivos.

$\mathrm{Na}$ mesma época, de acordo com Lassala (2017, p. 88), surgem repetidamente algumas inscrições de "cão fila Km 26" nas ruas da cidade de São Paulo, sendo muito comum também o aparecimento de poemas, palavras bem-humoradas e frases enigmáticas nos muros. Para ele, essas seriam as primeiras inscrições na capital paulista que mais tarde seriam classificadas como pichação e utilizadas, em alguns momentos, como uma espécie de propaganda irregular ou simplesmente com intenções artísticas para chamar atenção dos transeuntes.

Vários são os significados da palavra pichação (PICHAÇÃO, 2020): ato ou efeito de pichar; inscrição ou rabisco, geralmente de teor político, em fachadas e edifícios; tecer comentário crítico. O professor e designer Gustavo Lassala (2017, p. 46) define o conceito de pichação como uma ação de transgressão, utilizada para marcar presença ou chamar atenção para si ou para alguma causa, principalmente em ambientes do espaço público. Para ele, é uma prática que não define um padrão estético quanto à forma e ao conteúdo, privilegiando o uso da palavra ou tipografia, além disso o tempo de realização do ato é curto e, portanto, a produção em si é aleatória e anárquica.

É importante ressaltar que, para evitar equívocos semânticos, existe uma distinção entre o termo pichação, grafado com "ch", e pixação, escrito com “x”, termos esses encontrados em 


\section{Revista de Estudos Acadêmicos de Letras}

alguns livros, artigos ou reportagens. A pichação designa a atuação de qualquer pessoa no simples ato de rabiscar, escrever e pintar em muros, utilizando das mais diversas ferramentas. Por sua vez, a pixação apresenta-se como um tipo específico da prática de pichar:

Pixação refere-se a um tipo de intervenção urbana ilegal nativa de São Paulo; sua principal característica é o desenho de letras retilíneas escritas com spray ou rolo de espuma para estampar logotipos de gangues ou indivíduos; esse estilo de letras é conhecido como tag reto. Normalmente moradores de bairros periféricos, jovens que se arriscam nessa modalidade ao escalar edificações para carimbar sua marca em lugares de grande visibilidade, buscam notoriedade (LASSALA, 2014, p. 20).

A partir desses conceitos, pode-se compreender que o pichador dialoga em diferentes intensidades com a sociedade. A linguagem da pichação e sua lógica são representadas por vários tipos de grafismos, sendo os mais comuns no Brasil o tag reto e o xarpi. Esses funcionam, aparentemente, como um instrumento de comunicação próprio de cada comunidade, assim os pichadores produzem as manifestações gráficas, na maioria das vezes, para aqueles que compreendem a linguagem da pichação.

O tag reto é um estilo de letra a qual é caracterizada por ter o traçado predominantemente reto, com formas pontiagudas e estendidas. Conforme sustenta Lassala (2017, p. 110), o tag reto foi difundido pelos pichadores de São Paulo e é usado para padronizar um logotipo, além de surgir como elemento diferenciador de grupos ou gangues que buscavam desenhos próprios com a possibilidade de ocupar o maior espaço possível no suporte.

O termo tag é uma palavra de origem inglesa, cujo significado basicamente é etiqueta ou rótulo, no entanto pode ter outros sentidos de acordo com a sua utilidade. Para os grafiteiros, é sinônimo de assinatura, frequentemente empregado para identificação do autor em trabalhos. Já, para a comunidade de pichadores, representa não só uma assinatura, mas também traz características que deram origem ao movimento tipicamente paulistano Tag Reto.

O Xarpi é um outro estilo de pichação e significa a inversão das sílabas da palavra "pixar". No trabalho de etno-reportagem sobre a pichação no Rio de Janeiro, Vieira (2009, p. 9) sustenta que a pichação carioca é determinada pelos traços curvos e pelo comportamento, com a violência passando a se concentrar apenas na forma simbólica. Nesse panorama, para a comunicação interna e com o objetivo de ludibriar a polícia e os moradores locais surgiu o dialeto TTK:

O mais conhecido de todos estes dialetos de caráter criptográfico é a "língua do TTK", que consiste em pronunciar as palavras invertendo a ordem das sílabas (pichador $=$ 


\section{Revista de Estudos Acadêmicos de Letras}

dorchapi). O TTK foi criado por presos políticos no fim dos anos 70, com a ditadura ainda em vigor. A intenção era despistar os militares e seus agentes. O nome é uma homenagem ao Catete, bairro em que a língua teve boa repercussão (TTK = KTT). Os pichadores se apropriaram do dialeto, dominaram-no e o colocaram em prática em diversos ambientes, no ônibus, na escola, na rua, causando curiosidade e espanto nas pessoas ao redor. Assim, ao mesmo tempo, transgrediam nos muros e subvertiam na língua [...] (VIEIRA, 2009, p. 82).

Embora essa linguagem não seja mais tão frequente nas manifestações, para Vieira (2009, p. 83) o TTK deixou vestígios no vocabulário do pichador no qual se encontram inúmeros neologismos como tala, tatin, xarpi, cialipo, lokitran (lata, tinta, pixar, polícia, tranquilo), incorporados ao atual jargão dessa comunidade de falantes, além de ter forte influência nos movimentos musicais de rap.

É interessante destacar que o contexto de manifestação política contra o regime militar nas décadas dos anos de 1970 e 1980 no Brasil colaborou para visão da pichação como uma forma de expressão da opinião e pretensão a favor da democracia. Desse modo, surge a visão da pichação como ação transgressora por natureza e sua associação a um tipo de protesto.

Aliada a uma grafia singular e aparentemente incompreensível, a percepção da pichação como protesto e ato de balbúrdia persiste até o presente momento, sendo motivo de estranhamento e preconceito aos olhos da sociedade. Com base nisso, pode-se destacar no processo de observação do ambiente urbano a pichação como elemento percursor da linguagem, colaborando para um exercício visual que orienta a ressignificação das paisagens nas cidades. 


\section{Revista de Estudos Acadêmicos de Letras}

\section{A PERSPECTIVA VARIACIONISTA}

De modo geral, a linguagem envolve a capacidade comunicativa do ser humano em compreender e desenvolver a língua e outras manifestações, tais como a dança, a música ou a arte. Já a língua é um sistema que acompanha a evolução da sociedade e reflete os padrões de comportamento que, eventualmente, podem mudar em razão do decorrer temporal. O professor José Lemos Monteiro (2000, p. 16) declara que a função social da língua de estabelecer contatos sociais e o papel de transmitir informações sobre o falante representa uma prova cabal acerca da existência de uma relação íntima entre língua e sociedade.

Essa relação revela-se de tamanha complexidade, posto que trouxe diversas discussões ao campo da linguística no que tange aos pressupostos teórico-metodológicos sobre o comportamento dos indivíduos no uso da linguagem. A sociolinguística, como comumente ficou conhecida, confronta os conceitos resultantes dos modelos saussuriano e gerativista e pressupõe que a sistematicidade da linguagem é buscada por meio do estudo da variação linguística.

A sociolinguística é a área de estudo que observa as situações reais de uso da língua, considerando as relações entre a estrutura e os aspectos socioculturais envolvendo a produção linguística. Tem-se, diante disso, a importância da linguagem, de pequenos grupos a comunidades maiores, visto que destacam-se temas envolvendo a diversidade linguística, a dialetogia, a crioulística e os estudos da interação.

Tal abordagem, também chamada de Teoria da Variação e Mudança, consolidou-se inicialmente nos Estados Unidos, na década de 1960, com o linguista William Labov, a fim de possibilitar a observação da regularidade e da sistematicidade das variantes linguísticas, presentes na comunicação do dia a dia. Em suma, a professora Maria Cecilia Mollica traz uma compreensão mais clara sobre o foco da sociolinguística:

A sociolinguística considera em especial como objeto de estudo exatamente a variação, entendendo-a como um princípio geral e universal, passível de ser descrita e analisada cientificamente. Ela parte do pressuposto de que as alternâncias de uso são influenciadas por fatores estruturais e sociais. Tais fatores são também referidos como variáveis independentes, no sentido que os usos de estruturas linguísticas são motivados e as alternâncias configuram-se por isso sistemáticas e estaticamente previsíveis (MOLLICA, 2019, pp. 9-10).

A variação linguística é entendida como fenômeno essencial à própria natureza humana, dado o dinamismo da língua e os diversos fatores de natureza social ou estrutural que a 


\section{Revista de Estudos Acadêmicos de Letras}

influencia. O modelo laboviano permite compreender as estruturas linguísticas variantes apresentadas numa língua que revelam padrões de regularidade e, consequentemente, não são justificáveis pelo acaso.

Com base nisso, considera-se que "duas ou mais formas distintas de transmitir um conteúdo informativo constituem, pois, uma variável linguística. As formas alternativas, que expressam a mesma coisa num mesmo contexto, são denominadas variantes linguísticas" (MONTEIRO, 2000, p. 59). A perspectiva variacionista considera que a língua é dotada de heterogeneidade, pois é contemplada como um sistema de regras variáveis e categóricas que se comportam de modo frequente e previsível.

A fim de demonstrar explicações específicas para as mudanças sonoras na realização dos ditongos /aw/ e /ay/ na ilha de Martha's Vineyard, Labov (2008, p. 45) aponta que a centralização e o arredondamento dos ditongos estão associados a estímulos sociais que afetavam profundamente a vida na ilha, sendo necessário considerar: a presença de diferentes grupos étnicos; a localidade era o município mais pobre do estado de Massachussetts; apresentava alto índice de desemprego e alto índice de emprego temporário; a principal fonte de renda, pesca de baleias, em queda e o declínio da agricultura e da agropecuária.

Por esse ângulo, observa-se que as variáveis externas ou não linguísticas, tais como gênero/sexo, escolaridade, idade e classe social, dentre outras, relacionam-se a fenômenos de uso na fala e na escrita. $\mathrm{O}$ gênero, por exemplo, pode indicar diferenças de timbre, altura e ritmo que determinam as especificidades da voz feminina ou masculina. Para Monteiro (2000, p. 73), as análises sobre correlação entre gênero e variação linguística também podem indicar a preferência de mulheres pelo uso de formas associadas ao padrão de prestígio e status atribuído pela comunidade de fala.

A classe social e o grau de escolaridade do falante também constituem fatores importantes para uma pesquisa linguística em vários níveis, seja fonológico, sintático, morfológico ou lexical, pois exerce fortes influências no modo de falar da comunidade. Em um caso concreto, na obra de William Labov (2008), foram examinados diversos elementos dessa natureza sobre os traços do inglês padrão e não padrão, constatando que o Black English vernacular é uma variedade do inglês extremamente estigmatizada e sofre preconceito devido a pressões étnicas, escolarização e classes sociais. 


\section{Revista de Estudos Acadêmicos de Letras}

As mesmas técnicas de observações de usos da língua em situações espontâneas foram aplicadas no estudo sobre a estratificação social do /r/ em Nova York e deram suporte às conclusões da proposta variacionista. Labov (2008, pp. 60-61) destaca que as pressões e as atitudes sociais incidem sobre as estruturas linguísticas, de modo que a manifestação do falante sofre constrições diante da possibilidade de avaliação da postura articulatória.

Em razão disso, Labov (2008, p. 244) salienta a presença do paradoxo do observador na pesquisa linguística, visto que o objetivo de investigação na comunidade deve ser esclarecer como as pessoas falam quando não estão sendo sistematicamente observadas, no entanto os dados de estudo da variação linguística só podem ser obtidos se a observação for sistemática. Para isso, são utilizados vários procedimentos que desviam a atenção do falante no momento da entrevista para que o vernáculo em análise emerja.

Do mesmo modo, essa compreensão pode ser destinada à análise de grafismos urbanos, pois as pichações são produções linguísticas podem contribuir na observação de uso da linguagem, seja na modalidade oral, seja na modalidade escrita. As pichações podem revelar elementos morfológicos, lexicais ou discursivos para a pesquisa e permitir considerações relevantes para o campo da linguística.

\section{A LINGUAGEM DAS RUAS DE MANAUS}

As grandes metrópoles, além de exercerem fortes influências econômicas, políticas e sociocultural sobre outras cidades, são marcadas por diferentes estímulos visuais, o que abrange outdoors, letreiros luminosos, placas de estabelecimentos comerciais e propagandas. Tudo isso pressupõe uma intensa interação entre os diferentes níveis lexicais, enunciativos e discursivos da leitura durante o cotidiano brasileiro.

As pichações têm sido consideradas formas de intervenção do espaço urbano e, como resultado, pode-se inferir que esse discurso escrito se materializa de um contato ideológico e linguístico. Quanto a isso, ao traçar uma interface entre a Sociolinguística e a Análise do Discurso, Tania de Souza (2016, pp. 125-128) sustenta que, embora a sociolinguística estude a variação a partir da interação entre os níveis sintáticos, lexicais e morfológicos, com a análise do discurso, é possível explicar essa interação por meio da análise dos processos discursivos que também compõem um texto. 
Para Orlandi (2002, pp. 15-16), a Análise do Discurso compreende a linguagem como mediação necessária entre o homem e a realidade social. Mediação essa realizada pelo discurso, isto é, pelas práticas discursivas as quais envolverm as formações sociais dos sujeitos. Ao considerar o discurso como objeto de investigação, a Análise do Discurso relaciona a linguagem à exterioridade, de modo que o estudo é voltado às produções de sentido estabelecidas pelo uso da língua. Assim, as representações nas figuras coletadas refletem construções discursivas as quais implicam uma significativa relação com formações ideológicas.

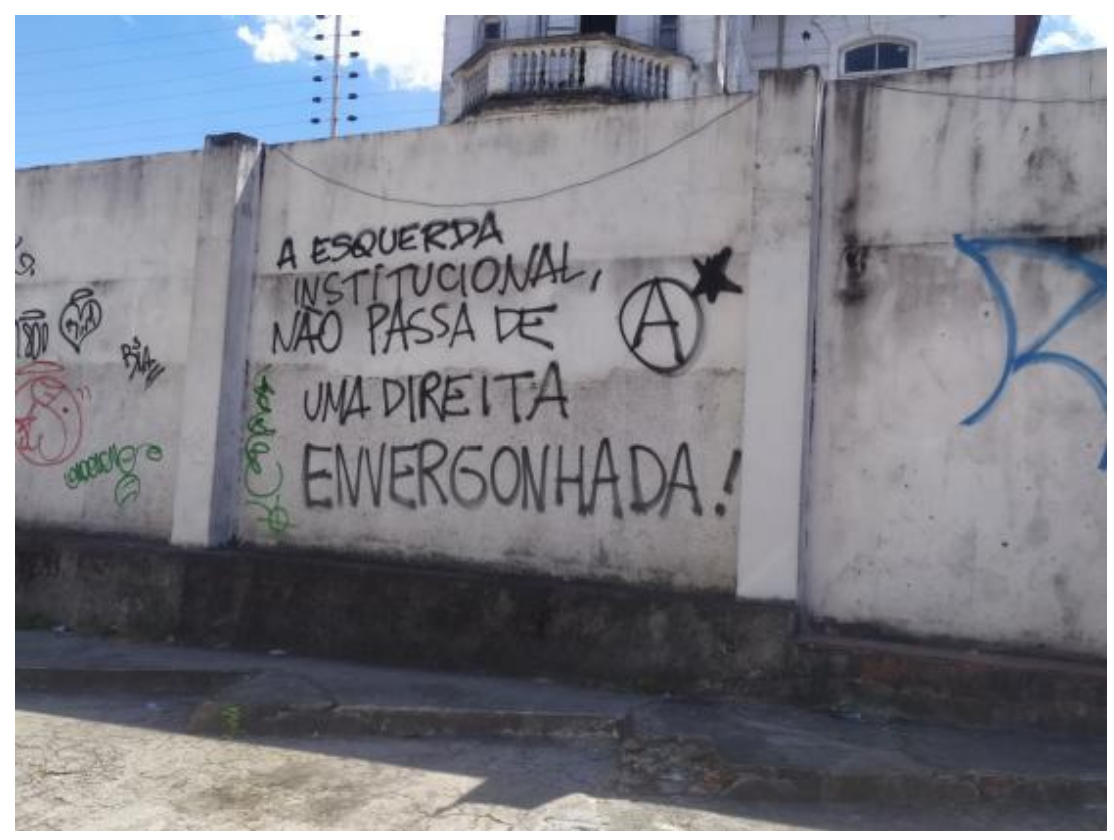

Figura 1. Pichação na Av. Leonardo Malcher, Centro de Manaus. Coletada em jul. 2020.

Fonte: Fotos da autora

A pichação (fig. 1) é uma crítica ao cenário político brasileiro, evidenciando a polarização das instituições políticas no país. As palavras “esquerda" e "direita” representam uma divisão ideológica de dimensões sociológicas, econômicas e religiosas enquadrada aos partidos políticos. Essa inscrição no muro é um trecho de um comunicado Zapatista realizado pelo subcomandante Marcos, do Exército Zapatista de Libertação Nacional, em um manifesto de 22 de setembro de $2007^{2}$.

2 Trecho "La izquerda institucional no es mas que una derecha vergonzante, una derecha con aval ilustrado" no Manifesto zapatista de setembro de 2007. Disponível em: < http://enlacezapatista.ezln.org.mx /2007/09/23/comunicado-del-ccri-cg-del-ezln-del-22-de-septiembre/>. Acesso em: jul. 2020 


\section{Revista de Estudos Acadêmicos de Letras}

A declaração é proveniente do porta-voz do movimento zapatista, de destaque internacional na década de 1990, devido à mobilização de camponeses e indígenas em prol de transformações nas políticas públicas voltadas à classe pobre e à urgência de uma reforma agrária no México. Por consequência, pode-se afirmar que o seguimento pichado no muro da cidade de Manaus conduz o leitor a uma correlação com um discurso de preocupação política.

Não se deve confundir, nesse caso, intertextualidade e interdiscursividade. Chama-se intertextualidade o "processo pelo qual o enunciador constrói seu texto (texto meta) mediante a incorporação ou transformação da totalidade ou de parte de outro texto (texto fonte)" (AZEREDO, 2013, p. 96), isto é, trata-se de relações dialógicas materializadas em textos. Ao passo que o conceito de interdiscurso está relacionado à memória discursiva:

O interdiscurso é todo conjunto de formulações feitas e já esquecidas que determinam o que dizemos. Para que minhas palavras tenham sentido é preciso que elas já façam sentido. E isto é efeito do interdiscurso: é preciso que o que foi dito por um sujeito específico, em um momento particular se apague na memória para que, passando para o 'anonimato', possa fazer sentido em 'minhas palavras' (ORLANDI, 2002, pp. 33-34).

O trecho referente ao movimento mexicano traz pleno sentido ao ser representado no muro da cidade, considerando o contexto imediato no país e a frequente circulação dessa expressão também em redes sociais. Apresenta-se de fato como um excerto sem menção a um enunciador anterior e que produz sentido neste lugar de interação. À vista disso, o interdiscurso "disponibiliza dizeres que afetam o modo como o sujeito significa em uma situação discursiva dada" (ORLANDI, 2002, p. 31).

Nessa perspectiva, observa-se que o pichador atua como um sujeito que está ligado ao seu espaço social e histórico, estabelecendo a interação entre discursos por meio dos grafismos urbanos e, no que diz respeito a isso,

[...] toda palavra se dirige a um interlocutor e estabelece um diálogo. Uma enunciação, qualquer uma, pode ser compreendida como uma réplica ao diálogo social. Uma pichação é uma resposta a alguma enunciação anterior, seja numa fala anterior voltada para si, seja na exterioridade do mundo (FERNANDES, 2011, p. 242-243). 


\section{Revista de Estudos Acadêmicos de Letras}

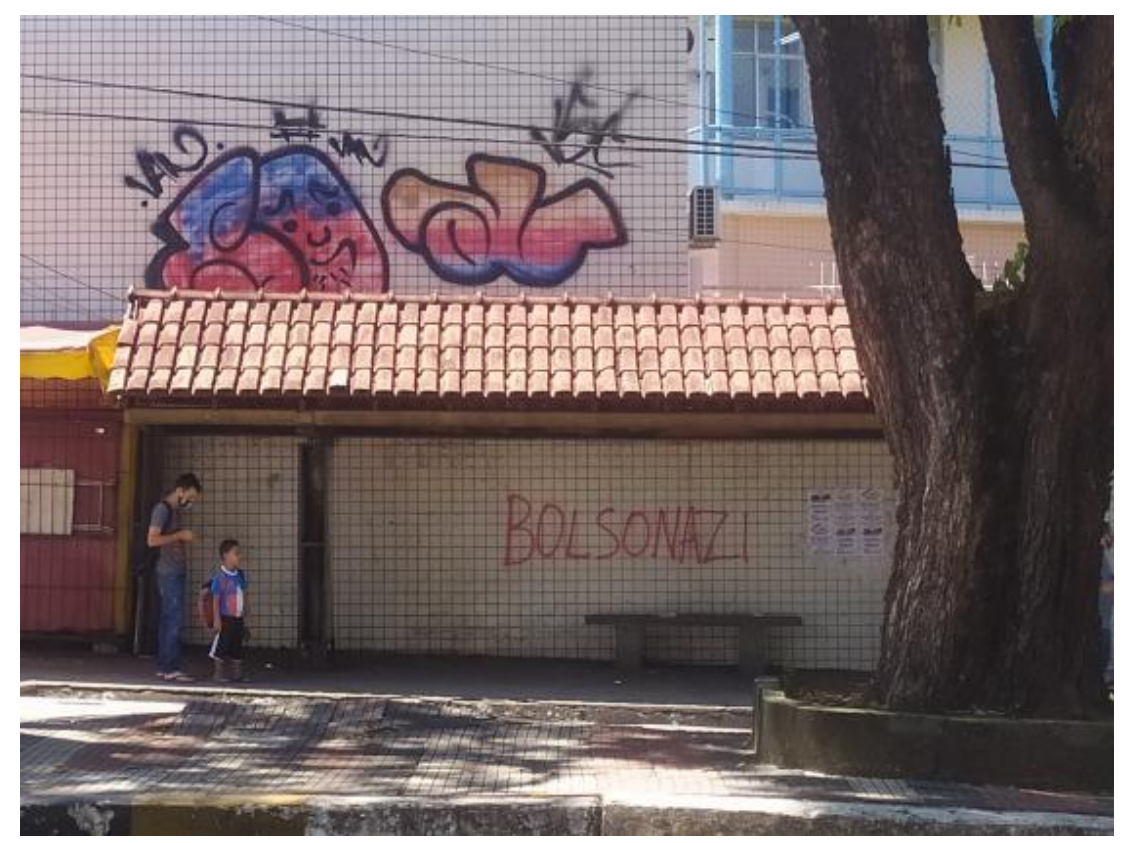

Figura 2. Pichação na Av. Getúlio Vargas, Centro de Manaus.

Coletada em jul. 2020.

Fonte: Fotos da autora.

Inicialmente, ao analisar a expressão "bolsonazi” (fig. 2), o leitor, usuário do transporte público e transeunte, associa também a uma concepção crítica dado o panorama político brasileiro dos últimos cinco anos. O trecho envolve o processo de formação e significação de palavras da língua portuguesa, em específico trata-se de "caso especial de composição [por aglutinação] em que a nova unidade resulta da combinação de parte de cada um dos dois termos [...]" (BECHARA, 2009, p. 372).

As palavras "Bolsonaro" e "nazismo" originam uma outra palavra, "bolsonazi", de intenso conteúdo lexical. Em uma primeira leitura, a interpretação pode aparentar ser excessiva, em razão da correlação entre a imagem do atual presidente com uma ideologia ultranacionalista e ligada ao liberalismo social. No entanto devem ser considerados o contexto imediato da enunciação, isto é, as circunstâncias ocorridas no Brasil à época das eleições presidenciais de 2018.

A expressão é utilizada até os dias atuais para mencionar a pessoa de Jair Messias Bolsonaro e aos adeptos de suas concepções e atitudes. O referido termo foi bastante propagado na rede social twitter durante campanhas presidenciais desde 2016 com a finalidade de expor os desentendimentos entre parlamentares e o atual presidente, as opiniões desse contrárias aos 


\section{Revista de Estudos Acadêmicos de Letras}

direitos humanos, casos de descortesia com jornalistas e dentre outras situações de impolidez envolvendo Bolsonaro e sua família.

O tom intimidador de seus pronunciamentos eleitorais e presidenciais suscitou uma onda de comentários divergentes da população que apontaram as reflexões de Bolsonaro e seus filhos como inflexíveis e intolerantes, considerando a diversidade de grupos minoritários étnicos, culturais, de sexualidade, dentre outros presentes na sociedade brasileira. Por essa razão, a expressão também foi relacionada ao posicionamento ideológico de quem o segue.

Destaca-se que o contexto socio-histórico e ideológico é, se pensado em um sentido amplo, também condição de produção do discurso, conforme argumenta Orlandi (2002). Por esse ângulo, deve ser observado que a defesa da intervenção estatal mínima no âmbito econômico e a preservação das instituições brasileiras familiares, religiosas e costumes de um modo geral são argumentos do viés político de Bolsonaro. As políticas públicas iniciais do atual governo ativeram-se ao combate da discussão de ideologia de gênero e a implementação de mudanças legislativas trabalhistas.

A hashtag (\#) bolsonazi tornou-se um termo o qual pode ser pesquisado em redes sociais todas as publicações associadas a essa problematização. Trata-se de uma estratégia astuciosa para fazer com que o conteúdo propagado nas publicações marcadas com a hashtag impacte mais pessoas e popularize a discussão. Pode-se dizer, assim, que a ideologia é condição para a constituição do sujeito e dos sentidos, consoante afirma Orlandi (2002, p. 46).

Para a professora Orlandi (2002), a ideologia aparece como efeito da relação necessária entre o sujeito com a língua e com a história para que haja sentido, por isso não pode ser vista apenas como um conjunto de representações ou como visão de mundo. O trabalho da ideologia na produção discursiva é "produzir evidências, colocando o homem na relação imaginária com suas condições materiais de existência” (ORLANDI, 2002, p. 46).

É importante ressaltar que a presente pesquisa é de caráter etnográfico, a fim de assimilar os recursos linguísticos empregados nas práticas de pichação na capital amazonense. Em relação a isso, foram colhidas em torno de cento e vinte imagens no Centro de Manaus e localidades adjacentes, considerando que são áreas de grande trânsito de pessoas e onde podem ser observados a atuação de diferentes grupos de pichadores. Consequentemente, tem-se a 


\section{Revista de Estudos Acadêmicos de Letras}

possibilidade de identificação de produções discursivas, perceptíveis pela estrutura, marcas e produções de sentido distintos na região.

O material gráfico presente na cidade manauara conduz a observação de um conjunto de discursos diferentes em seu processo de interlocução, o qual estabelece relações entre os sujeitos, a cultura e a história. A respeito disso, pode-se constatar outra manifestação textual em muros e casas, grafadas com tintas pretas ou vermelhas, para destacar a ação de facções criminosas.

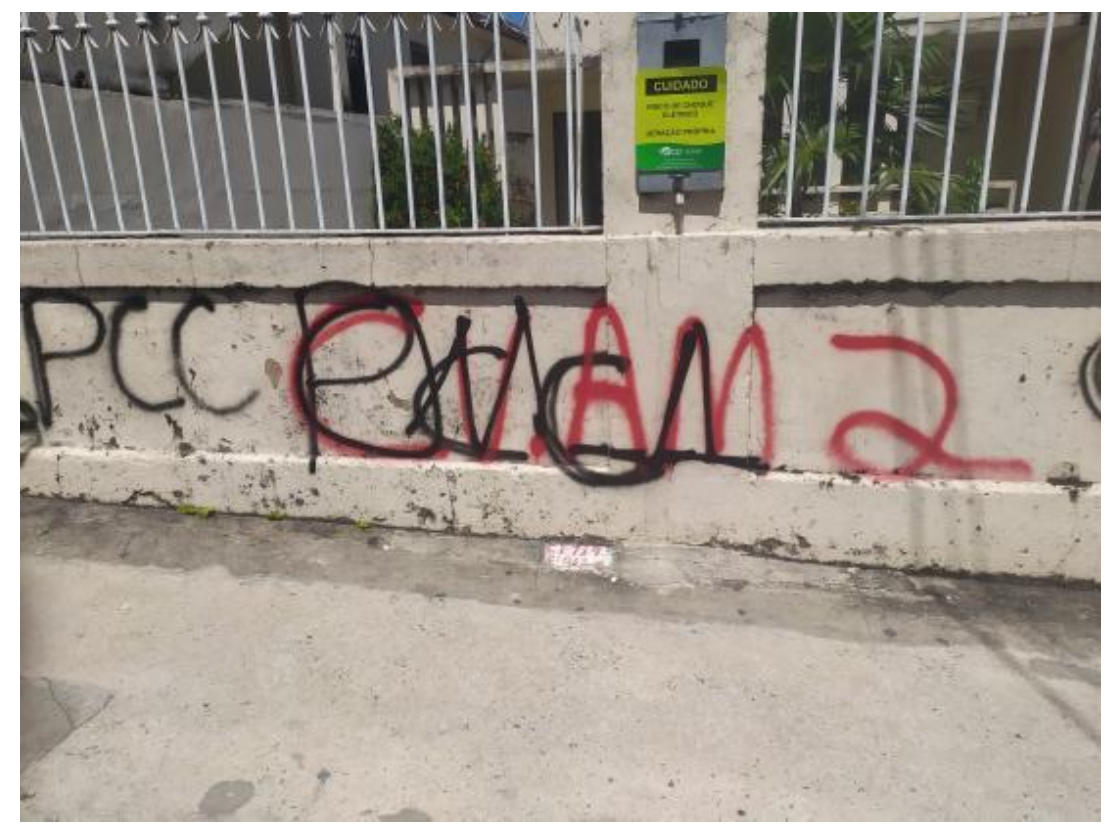

Figura 3. Pichação em fachada de casa na Rua Comendador Alexandre Amorim, Nossa Sra. Aparecida. Coletada em jul. 2020.

Fonte: Fotos da autora.

As inscrições (fig. 3) apresentam a forma abreviada de palavras e expressões referente às organizações criminosas que atuam no Estado do Amazonas e nas regiões de fronteiras. Vê-se que as abreviações são bastante recorrentes nas disputas por muros e fachadas de prédios em Manaus, pois revelam praticidade e rapidez no momento de pichar. Desse modo, "pode-se incluir como caso especial da abreviação o processo de se criarem palavras, com vitalidade no léxico, mediante a leitura (isoladas ou não) das letras que compõem siglas [...]" (BECHARA, 2009, p. 371).

As siglas em uso PCC, CV e FDN (fig. 4) referem-se aos grupos de narcotráfico respectivamente Primeiro Comando da Capital, Comando Vermelho e Família do Norte. Tais facções, como se denominam, litigam pelas principais rotas marítimas do tráfico de cocaína e, 


\section{Revista de Estudos Acadêmicos de Letras}

para compreender essa problematização de segurança pública, é necessário ponderar alguns aspectos geográficos da região amazônica.

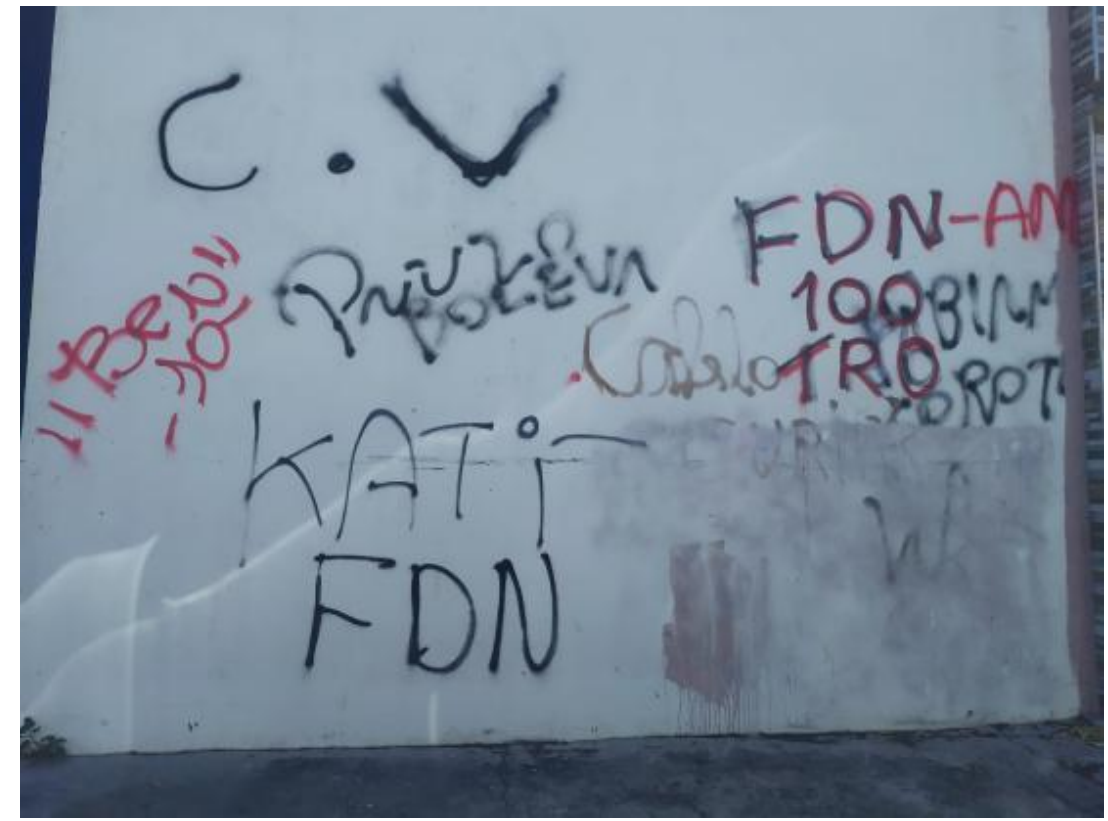

Figura 4. Pichação em muro na Rua Monsenhor Coutinho, Centro. Coletada em jul. 2020.

Fonte: Fotos da autora.

É sabido que o Amazonas faz divisa com outros cinco estados da federação, entre eles Roraima, Pará, Rondônia, Mato Grosso e Acre, além de possuir áreas de fronteiras com Colômbia, Venezuela e Peru. Considerando a dimensão da bácia hidrográfica amazônica, o transporte mais comum entre as cidades amazonenses é feito por via fluvial. As nascentes dos Rios Solimões e Japurá encontram-se em território peruano e colombiano e deságuam em regiões brasileiras, por isso tais afluentes são conhecidas como os principais caminhos para escoar a produção de droga.

O centro da capital amazonense exerce função importante na atuação do narcotráfico, em razão da localização do Porto de Manaus constituir uma significativa área portuária na região. Diante disso, é frequente o ato de pichar, marcar casas e lojas para delimitar a extensão da atividade de tráfico de entorpecentes de cada grupo criminoso. O fato é que tais pichações demonstram a intensa disputa desses grupos pelo controle da atividade principalmente no centro e, consequentemente, em outros bairros da cidade. 


\section{Revista de Estudos Acadêmicos de Letras}

Pode ser observado (fig. 3) que, assim como os pixadores, os grupos criminosos também utilizam do atropelo como um mecanismo para defender e legitimar seu local de atuação. Para Lassala (2017, pp. 138-139), atropelar significa escrever por cima de outra pixação e isso acontece como afronte e desrespeito ao pixador adversário. Ainda segundo o autor, uma pixação atropelada é um aviso ao pixador de que naquele local concorrem com outros grupos de pixadores.

Expressões como "Aqui é FDN Zé" ou "Fulano é FDN" (fig. 5) são construções sintáticas bastante presentes na oralidade da comunidade amazonense, principalmente no ambiente trangressor. Com isso, podem ser observadas que há reflexos dessas manifestações orais nas pichações, indicando, por meio das siglas, que determinada pessoa ou determinado bairro pertença a um grupo específico ligado ao tráfico de drogas.

\section{‘Aqui é FDN Zé', diz traficante na cara da polícia em Manaus}

Em tempo.

Fonte: Matéria de maio de 2019 da coluna prisões do jornal Em tempo. Disponível em: <https://d.emtempo.com.br/policia/148780/aqui-e-fdn-zediz-traficante-na-cara-da-policia-em-manaus>. Acesso em: ago. 2020.

Além disso, o transeunte na cidade manauara pode constatar a coexistência de uma terceira representação de discurso: as pixações (fig. 6 e fig.7). Com recursos de tag reto, bomb ou grapixo, essas incrições utilizam-se de múltiplos traços, grafias, cores e interagem com os demais grafismos, de modo que as expressões são associadas às produções de diferentes círculos sociais.

Revela-se no ambiente urbano um excesso de informação aos indivíduos que coabitam na localidade central de Manaus, de maneira que o diálogo estabelecido entre sujeito e discurso ocorre por um embate sobre a utilização dos espaços da cidade. Como resultado, "os pichadores produzem para aqueles que compreendem a linguagem da pichação e suas simbologias; eles não possuem interesse de dialogar com outras categorias externas" (AZEVEDO, 2014, p. 44). 


\section{Revista de Estudos Acadêmicos de Letras}

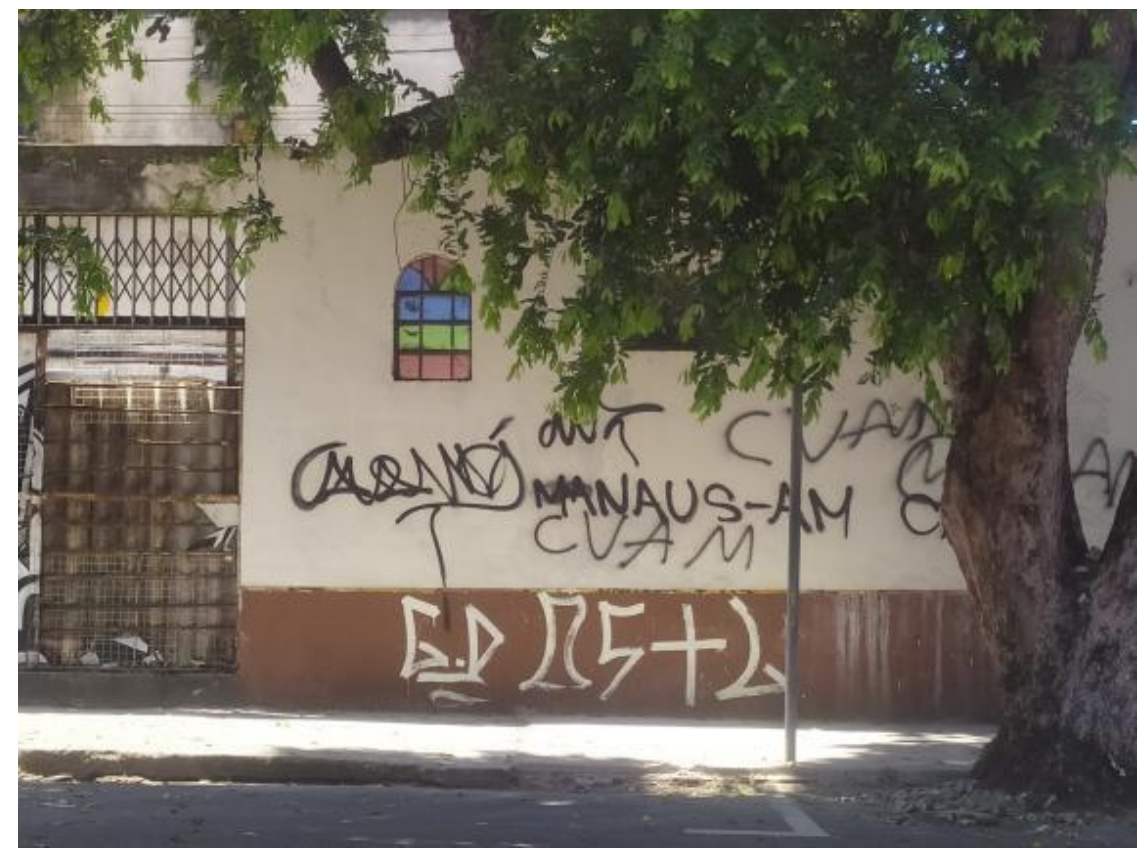

Diferentes traços de picho encontrados na esquina da

Rua Ferreira Pena com a Rua 10 de Julho, Centro de Manaus.

Coletada em jul. 2020.

Fonte: Fotos da autora.

É muito frequente a ocorrência de grafismos urbanos com estilos de caligrafias praticamente ilegíveis, o que chamamos de nomes ou grifes. Nomes são geralmente constituídos por siglas e, para Lassala (2017, pp. 114-116), podem aparecer como abreviações, nomes pessoais, codinomes que servem para reconhecimento dos feitos de pixadores individuais, ao passo que grifes são um nome ou uma forma pictórica de representação de um grupo de interventores.

Sob esse contexto manauara, observa-se que as pixações são realizadas com o intuito recreativo, o que Lassala (2014) indica como "rolês" os passeios curtos e descontraídos desses interventores para a elaboração de suas expressões visuais. Encontram-se muitas semelhanças entre as manifestações de grupos criminosos e as produções de pichadores, tais como o atropelo, as grifes e os nomes. Pode-se afirmar que esses são recursos utilizados por ambos os grupos, ainda que involuntariamente. 


\section{Revista de Estudos Acadêmicos de Letras}

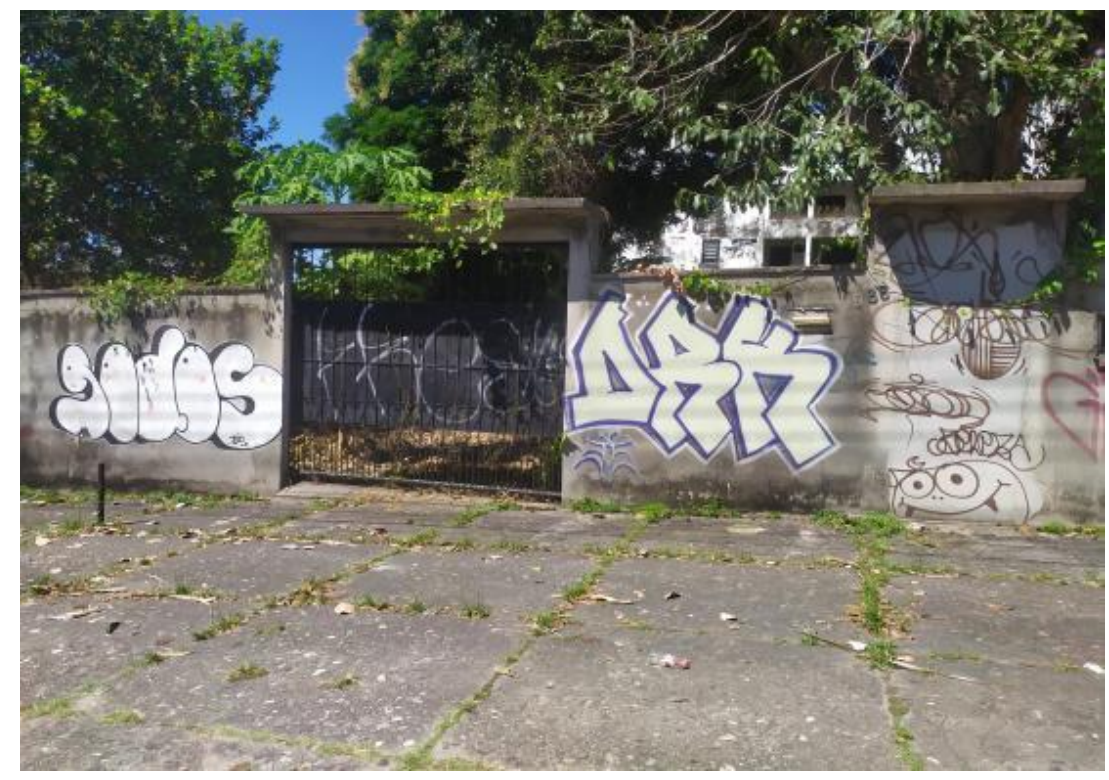

na Av. Silves, Cachoerinha.

Figura 7. Pixação Coletada em jul. 2020.

Fonte: Fotos da autora

Destaca-se também que a representação do pixo na cidade de Manaus possui uma tendência a um esvaziamento sígnico, isto é, não há como um transeunte assimilar significados ou intelecção das inscrições. À vista disso, não se pode afirmar que a pixação não interage ou não estabelece qualquer tipo de comunicação com a sociedade, pois a força intervencionista reside justamente no próprio ato de pixar. Consequentemente, a rejeição do público em geral consiste na falta de compreensão das expressões, bem como na limitação da prática da pixação a círculos sociais marginalizados.

Tendo em vista a definição de discurso, a professora Orlandi (2002, p. 15) conceitua o discurso como palavra em movimento, prática de linguagem e mediação que torna possível a transformação do homem e da realidade em que ele vive. Nesse sentido, "o discurso é o lugar em que se pode observar essa relação entre língua e ideologia, compreendendo-se como a língua produz sentidos por/para os sujeitos" (ORLANDI, 2002, p. 17).

Para Dominique Maingueneau (2015, p. 23-26), a noção de discurso não é estável e comumente o discurso é definido como o uso da língua. O discurso é uma organização para além da frase, o que significa dizer que o discurso não se trata apenas de uma sequências de palavras que transmitem a informação, mas sim uma forma de ação, interativo e contextualizado, que atua como construtor social de sentido. 


\section{Revista de Estudos Acadêmicos de Letras}

O professor Maingueneau (2015), ao tratar sobre os aspectos relevantes sobre o discurso, sustenta a importância do efeito eu/aqui/agora na produção de dizeres e sentidos:

o discurso só é discurso se estiver relacionado a um sujeito, a um EU, que se coloca ao mesmo tempo como fonte de referências pessoais, temporais, espaciais (EU-AQUI-AGORA) e indica qual é a atitude que ele adota em relação ao que diz a seu destinatário (fenômeno da modalização) (MAINGUENEAU, 2015, p. 27).

Dessa forma, pode-se afirmar que essa relação gera efeitos de subjetividade nos discursos, isto é, projetam-se as categorias de pessoa, espaço e tempo no momento da enunciação. Segundo Maingueneau (2015), o sentido dessa relação eu-aqui-agora não se constitui apenas de referentes recuperáveis na situação imediata de enunciação, mas também de referentes discursivos.

\section{CONSIDERAÇÕES FINAIS}

Os grafismos urbanos contribuem para a construção dos sujeitos e para a modificação do contexto em que esses sujeitos estão inseridos, pois a interação de expressões visuais revela as interfaces da sociedade, da história e da cultura. Pichar a cidade é, além de inscrever uma assinatura, atuar num gesto intervencionista de cunho político, social e artístico. A pichação estabelece um diálogo social em continuidade, de modo que determinados grupos geram um conjunto de formas discursivas em seu processo de comunicação.

A presente pesquisa considera a pichação como um importante mecanismo nas práticas sociais de uso da linguagem, visto que há uma desconstrução sobre a concepção de arte de rua. Os grafismos urbanos na cidade manauara, se entendidos como gênero discursivo, comportam temáticas sobre a preocupação político-social, a insegurança pública e a manifestação artística considerada muitas vezes subversiva.

Sob essa perspectiva, pode ser observado que a pichação e o grafite são recursos muito utilizados no cotidiano como forma de manifestação artística. A pesquisa expõe também a pichação como prática social pouco prestigiada pela sociedade, de modo que materiais bibliográficos e dissertações etnográficas sobre a arte de rua são escassos, além de existir um parco campo de pesquisa em instituições de ensino.

A classe social, o grau de escolaridade dos falantes da língua portuguesa, a idade, o gênero, os índices de criminalidade da localidade em estudo, dados demográficos e dados 


\section{Revista de Estudos Acadêmicos de Letras}

econômicos sobre a população são fatores que podem ser considerados em um estudo sobre os fenômenos linguísticos de determinada região. A Sociolinguística aplica-se em um estudo descritivo sobre o comportamento linguístico dos membros de uma comunidade e, considerando a extensão da cidade de Manaus, com sessenta e três bairros, bem como a influência do dialeto amazonês, a pesquisa demanda maior coleta de dados a fim de que se possa gerar resultados concretos.

Por essa razão, a perspectiva da Análise do Discurso pôde se mostrar proveitosa para o estudo, pois foi possível considerar o contexto de construção dos discursos, os sentidos empregados nos grafismos e as estruturas ideológicas por trás das manifestações em muros e prédios da região central de Manaus. A partir dessa abordagem, são observados diversos elementos da paisagem local que apontam para formações discursivas relacionadas às situações políticas, ideológicas e sociais da sociedade manauara.

\section{REFERÊNCIAS BIBLIOGRÁFICAS}

AZEREDO, José Carlos de. Gramática Houaiss da Língua Portuguesa. 3 ed. São Paulo: Publifolha, 2013.

AZEVEDO, Vinicius Moraes de. A carreira da pichação em etapas de (des)envolvimento. Revista Habitus: Revista de Graduação em Ciências Sociais do IFCS/UFRJ, Rio de Janeiro, v. 13, n. 1, p. 41-51, jul 2014. Semestral. Disponível em <https://revistas.ufrj.br/index.php/habitus/article/viewFile/11451/8401>. Acesso em: mar. 2020.

BECHARA, Evanildo. Moderna gramática portuguesa. 37 ed. Rio de Janeiro: Nova Fronteira, 2009.

FERNANDES, Eliane Marquez da Fonseca. Pichações: discursos de resistência conforme foucault. Acta Scientiarium: Language and Culture, Maringá, v. 33, ed. 2, p. 241-249, 2011. DOI 10.4025/actascilangcult.v33i2.13864. Disponível em: <http://periodicos.uem.br/ojs/index.php/ActaSciLangCult/article/viewFile/13864/13864>. Acesso em: jul. 2020.

FRANCO, Sérgio Miguel. Iconografias da metrópole: grafiteiros e pichadores representando o contemporâneo. 2009. 175 f. Dissertação (Mestrado em Arquitetura e Urbanismo) - Universidade de São Paulo, São Paulo, 2009. DOI 10.11606/D.16.2009. tde-18052010-092159. Disponível em: 


\section{Revista de Estudos Acadêmicos de Letras}

<https://www.teses.usp.br/teses/disponiveis/16/ 16136/tde-18052010-092159/pt-br.php.>. Acesso em: abr. 2020.

GITAHY, Celso. O que é graffiti. 1 ed. São Paulo: Editora brasiliense, 1999.

LABOV, William. Padrões Sociolinguísticos. Tradução de M. Bagno, M. M. P. Scherre; C. R. Cardoso. São Paulo: Parábola Editorial, 2008 [1972].

LASSALA, Gustavo. Em nome do pixo: a experiência social e estética do pichador e artista Djan Ivson. 2014. 102 f. Tese (Doutorado em Arquitetura e Urbanismo) - Universidade Presbiteriana Mackenzie, São Paulo, 2014. Disponível em: http://tede.mackenzie.br/jspui/handle/tede/2554\#preview-link0. Acesso em: abr. 2020.

LASSALA, Gustavo. Pichação não é pixação: uma introdução à análise de expressões gráficas urbanas. 2 ed. São Paulo: Altamira Editorial, 2017.

MOLLICA, Maria Cecília. Fundamentação teórica: conceituação e delimitação. In: MOLLICA, Maria Cecília; BRAGA, Maria Luiza (Orgs.). Introdução à sociolinguística: o tratamento da variação. 4 ed. São Paulo: Editora Contexto, 2019. p. 9-14.

MAINGUENEAU, Dominique. Discurso e análise do discurso. Tradução de Sírio Possenti. 1 ed. São Paulo: Parábola Editorial, 2015.

MONTEIRO, José Lemos. Para Compreender Labov. 1 ed. Petrópolis: Vozes, 2000.

ORLANDI, Eni Puccinelli. Análise de discurso: princípios \& procedimentos. São Paulo: Pontes, 2002.

PICHAÇÃO. In: DICIO, Dicionário Online de Português. Porto: 7Graus, 2020. Disponível em: <https://www.dicio.com.br/pichacao/>. Acesso em: mar. 2020.

PICHAÇÃO. In: DICIONÁRIO da Língua Portuguesa. Lisboa: Priberam Informática, 2020. Disponível em: <https://www.dicionario.priberam.org/pichação/>. Acesso em: mar. 2020.

SOUZA, Tania C. Clemente. Sociolinguística e Análise do Discurso. In: MOLLICA, Maria Cecília; FERRAREZI JUNIOR, Celso (Orgs.). Sociolinguística, Sociolinguísticas: uma introdução. São Paulo: Editora Contexto, 2016. p. 123-133.

VIEIRA, Jones. A galera do xarpi carioca. 2009. 126 f. Trabalho de Conclusão de Curso (Bacharelado em Comunicação Social) - Escola de Comunicação, Universidade Federal do Rio de Janeiro, Rio de Janeiro, 2009. Disponível em: https://pantheon.ufrj.br/bitstream/11422/2191/3/JVCOSTA.pdf. Acesso em: maio 2020. 